\title{
Moral Courage in Bicultural Contexts: The Need for Cultural Sensitivity in Practice
}

\author{
Jessica Hope and Mary Butler
}

\section{INTRODUCTION}

Occupational therapists in New Zealand work with increasingly culturally diverse populations. There is a need for practitioners to have adequate tools to work collaboratively with these clients and their whannau to provide equitable care. To avoid contributing to the already prevalent health disparities, we must respect clients' bicultural values and autonomy.

This essay explores an ethical issue that arose when I was presented with the opportunity to work with an elder Māori woman on a home visit, whom I will refer to as "Anne." I visited Anne to complete a home assessment following a fall. Before my arrival, I was directed by my supervisor to prepare some questions about culture to ask after the home assessment. I initiated the home assessment almost instantly upon arrival which led to Anne being very disengaged throughout the assessment, so her mokopuna (grandchild) did most of the talking. The home assessment was a non-standardised initial home assessment carried out from a westernised European perspective. It consisted of a general set of questions, followed by an observation of the client's home environment. This assessment was carried out the same way for each client; it was not adapted for use with other cultures, including the indigenous Māori culture, thus reflected a lack of collaboration and respect for Anne's bicultural values. However, there was a pivotal point within this interaction when I asked Anne for consent to address the questions regarding her culture. At this point, Anne's engagement shifted, and she became very willing to interact. Anne said that she had not been asked questions about her culture by a health practitioner before and began thanking me multiple times. Through her joy, I could see the value this held to her.

The contrasting engagement of Anne within the visit highlighted the importance of working collaboratively and respecting the client's bicultural values and autonomy. This experience was very confronting for me. I realised the importance of asking questions focusing on culture. However, usually, these questions do not get asked. If I were not directed by my supervisor to meet my competencies, I question whether we would have neglected to consider Anne's cultural values while also overlooking the need for collaboration when working in a bicultural context. This experience made me realise that courage might be needed to diverge from 'normal' practice routines to ensure equity and best practice with culturally diverse clients. Furthermore, this gives rise to the ethical issue of disregarding client bicultural values and autonomy when conflicting values are present.

\section{CRITICAL REFLECTION}

Kinsella, Park, Appiagyei, Chang, and Chow (2008) state that students in practice commonly observe conflicting values in practice leading to ethical tensions. These values can be shaped by various factors; for Anne, her values were shaped by her Māori identity (Kinsella et al., 2008). If these ethical tensions such as conflicting values are left unresolved, they pose implications for the client, which Aiken et al. (as cited in Bushby, Chan, Druif, Ho, \& Kinsella, 2015) states can decrease the quality of the client's care and overall health outcomes. 
Conflicting cultural values holds profound relevance for Māori as a minority culture in New Zealand. Jansen and Smith (2006), state that the New Zealand health systems reflect the dominant European culture and do not provide equal health outcomes for Māori. Bacal, Jansen, and Smith (2006) state that these health disparities have also been found to be partly due to the professional behaviour of our health care professionals. Parsons and Dickinson (2017) believe there is a moral vacuum, presenting in the delivery of bicultural care as a result of dominant cultures imposing their values in bicultural contexts. They also state that we need to be aware of our values and biases as these may have the capacity to override those of our clients (Parsons \& Dickinson, 2017). This statement reflects the possible override of Anne's values throughout the home assessment which imposed westernised perspectives; this impacted on the collaborative relationship between the client and practitioner as well as the overall quality of care.

Many Māori believe their way of living is their culture, and this influences their view on collaborative practices for health and wellbeing (Wepa, 2005, as cited in Wilson, 2008). Martin (2018) suggests that Māori can feel overlooked within the healthcare system. The value which Mãori place on working alongside health practitioners is often neglected (Health Quality \& Safety Commission [HQSC], 20I4).

The need for collaboration with the client and whānau in order to respect their bicultural values and autonomy also holds relevance in regards to New Zealand's founding document. Te Tiriti o Waitangi has influenced many of our practice environment policies and states Māori and non-Māori must form a partnership that benefits the whole community (Hopkirk, 2013). This document holds relevance within the occupational therapy competencies, specifically "working appropriately for bicultural Aotearoa New Zealand" and "building partnerships and collaborating" (Occupational Therapy Board of New Zealand, 2015a). Both these competencies state the need to work collaboratively with the client to ensure culturally competent care is given and the client's values and autonomy are respected. When working with Anne, these competencies were achieved by asking a few questions at the end of the visit. However, this was done as a task rather than a desired approach. This implementation of competencies could be improved through practitioners building rapport and asking simple questions regarding the client's cultural needs at the beginning of sessions.

When working with Māori, the first interaction is often the most important. Māori health Liaison Officer Querida Whatuira-Strickland states that just greeting the client with "Kia ora" can initiate the reduction of barriers presented by conflicting practitioner-client cultural values (HQSC, 20I4). I believe that doing this with Anne would have made an enormous difference when working with Anne. Initiating the engagement in a culturally sensitive way creates a sense of manaakitanga for the client, and it sets up a more collaborative therapeutic relationship (New Zealand Trade Manual, 20II). This will enable an understanding of their values and perspectives around care, as well as make practice decisions with collaboration and cultural sensitively, of which will also ensure good manaakitanga (Parsons \& Dickinson, 2017).

Ensuring a bicultural focus within practice has become even more relevant within the context of the Black Lives Matter movement and the occurrence of systematic racism within organisations leading to non-moral treatment and lack of autonomy (Diangelo, 2018). This movement resonates with minority groups within New Zealand and highlights the need for change (Walls, 2020). Within New Zealand health systems, Māori ability to exercise autonomy effectively is often undermined. Furthermore, this resonates with my ethical issue through the need for practitioners to provide culturally appropriate treatment and autonomy to culturally diverse clients to avoid disparities between races and provide collaborative care. It is said that the big picture systems in New Zealand designed from a westernised perspective seem almost designed to harm and fail Māori, Pasifika and people of colour. As demonstrated within the interaction with Anne, changes need to be made. Generalised approaches are not always effective and can hinder engagement and quality of care for clients (McConnell, 2020).

As occupational therapists, we must adhere to the Occupational Therapy Code of Ethics. The principle most relevant to the ethical issue described is Principle I regarding "relationship with those receiving occupational 
therapy services", specifically I.I "occupational therapists shall respect the autonomy of clients' roles in family, whānau and society, and enabling power and decision-making" (Occupational Therapy Board of New Zealand, 20I5b).

Disregard for client bicultural values and autonomy is explored here in relation to the Quadripartite Ethical Tool (QET). The QET is made up of four quadrants: deontology, utilitarianism, virtue ethics, and axiological ontology (Drolet \& Hudon, 2015). The ethical lens to which I have taken my issue is axiology which has a focus on values. Drolet (2014) states occupational therapy is founded on core values and that individuals are axiological beings. When working with Anne, it was clear that conflicting cultural values were evident. Furthermore, this interaction drew attention to the need to change westernised values. This shift was necessary in order to work collaboratively and competently with the client while also meeting the occupational therapy core values of equality and freedom (Drolet, 2014). Such a change in behaviour would respect client values and provide them with a sense of autonomy. The aim, as a new practitioner, is to develop my own sense of practitioner competence in way that commits to the values of fairness and impartiality, while enabling client choice, independence, initiative and self-direction. I hope, in this way, to put client centredness at the heart of my occupational therapy practice (Peloquin, 2007).

Within the context of the QET, I can see that my issue is primarily about values (axiology) (Drolet \& Hudon, 20I5). However it also aligns with utilitarianism, which was all about the cost effectiveness of a 'one size fits all' type of home assessment. This might fit within a westernised context, but did not have adequate nuance for a bicultural context.

From a deontological perspective, my work was also about ensuring that Anne had the opportunity to express her autonomy. This was done by asking questions regarding her culture. Finally, I felt a certain sense of moral courage underpinned the decision to address the bicultural issues in this home assessment. This moral courage reflects a type of virtue, which is the last quadrant in the QET. LaSala and Bjarnason (20I0) state that the ability to demonstrate moral courage can be improved through practice and I agree that the skills underpinning bicultural competence are likely to be enhanced by taking the chance to ask the right questions in future.

When I reflect on this experience, I have to ask myself the question: would I have addressed the bicultural context of Anne's life if it was not necessary in order to meet my practice competencies? I suspect that I would not have done it if I didn't have to. However, having done it I understand more about how I value the need for equitable care and client autonomy. The impact of working collaboratively while been culturally sensitive was so evident with Anne, it has made me realise that all us need to have the confidence ensure competent care is provided in a bicultural context.

I am now more aware that a bicultural focus can very easily be overlooked. My supervisor stated that she learned from observing my experience with Anne. This was very affirming and helped me to understand that we are all on this journey together. Upholding commitment to clients and advocating for their best interests requires moral courage and cultural sensitivity (Murray, 2010).

From an organisational level, there is need for better support and training for working in bicultural contexts to enable practitioners to enhance their cultural awareness, explore cultural biases (Parsons \& Dickinson, 2017), and meet the occupational therapy core value of client-centred practice (Peloquin, 2007). Kyler (2008) states that is there inadequate workplace and organisational support for bicultural practice. Training has also been said to correlate with improved competence and client satisfaction. I believe that further training would help with the process of finding moral courage in bicultural contexts enabling best practice and confidence to work collaboratively and culturally competently (Govere \& Govere, 2016). 


\section{CONCLUSION}

This article addressed the need to work collaboratively with clients while demonstrating the moral courage to ensure a bicultural focus. This experience emphasised the importance of respecting our client's values in practice, and I feel I have become more morally sensitised. I reflected on this experience, and understand that I was oblivious to the impact it would have on me and my future practice, as this experience has subsequently changed my perception on the importance of culturally competent and collaborative care.

Inequity within minority cultures is a prevalent issue within New Zealand. With the current Black Lives Matter movement, the need for change is being voiced louder than ever before. In conclusion, I highlight the need for organisations to support practitioners in enhancing their moral courage and cultural competence to ensure competent care is always provided, and that clients' values and the right to autonomy are met. I also highlight our individual responsibility to uphold a bicultural focus. As occupational therapists, we strive for client-centred care, and as a country, we aim to decrease health disparities present within our minority communities, but this can only be done if we harness the motivation to make changes both at an organisational and personal level.

Jessica Hope is a third-year Occupational Therapy student at Otago Polytechnic. She is always willing to learn and aspires always to give her all. She has always had a passion for helping people which influenced her goal of becoming an occupational therapist.

Mary Butler (@0000-0003-3365-8995) is Professor of occupational therapy, Otago Polytechnic, Dunedin. She works toward the development of sustainable approaches to issues of disability and rehabilitation. She enjoys working with students on authentic teaching and learning experiences, especially when this involves thinking about the ethics of practice.

Correspondence to: Jessica Hope. Email: Jessmhope98@gmail.com

\section{REFERENCES}

Bacal, K., Jansen, P., \& Smith, K. (2006). Developing cultural competency in accordance with the Health Practitioners Competence Assurance Act. New Zealand Family Physician, 33(5), 305-309.

Bushby, K., Chan, J., Druif, S., Ho K., \& Kinsella, E. A. (2015) Ethical tensions in occupational therapy practice: A scoping review. British Journal of Occupational Therapy, 78(4), 212-22I. https://doi.org/l0.1177/0308022614564770

Diangelo, R. (2018). White Fragility: Why it's hard for white people to talk about racism. London:Penguin Books Ltd.

Drolet, M. J. (2014). The axiological ontology of occupational therapy: A philosophical analysis. Scandinavian Journal of Occupational Therapy, 2/(1), 2-10. https://doi.org/10.3109/11038128.2013.831118

Drolet, M. J., \& Hudon, A. (2015). Theoretical frameworks used to discuss ethical issues in private physiotherapy practice and proposal of a new ethical tool. Medicine, Health Care, and Philosophy, 18(I), 5I-62. https://doi.org//0.1007/sII019-014-9576-7

Govere, L., \& Govere, E. (2016). How Effective is cultural competence training of healthcare providers on improving patient satisfaction of minority groups? A systematic review of literature. Worldviews On Evidence-Based Nursing, 13(6), $402-410$. https://doi.org/10.1111/wvn.12176

Health Quality \& Safety Commission. (2014, December 14). Communicating with Māori in a health setting [Video file]. Retrieved from https://www.youtube.com/watch?v=ocNhA_DMdIA\&list=PLqL5-6uWOmWcpnmUE9-RQB9BIDIg|LPrK\&index=2 
Hopkirk, J. (2013). E rua ngä ao, kotahi te taura tangata: Two worlds and one profession. New Zealand Journal of Occupational Therapy, 60(I), 5-15.

Jansen, P., \& Smith, K. (2006). Maori experiences of primary health care: Breaking down the barriers. New Zealand Family Physician, 33(5), 298-300.

Kinsella E. A., Park A. J., Appiagyei J., Chang E., \& Chow D. (2008) Through the eyes of students: Ethical tensions in occupational therapy practice. Canadian Journal of Occupational Therapy, 75(3), 83.

Kyler, P. (2008). Client-centered and family-centered care: Refinement of the concepts. Occupational Therapy in Mental Health, 24(2), 100-120. https://doi.org/10.1080/01642120802055150

LaSala, C. A., \& Bjarnason, D. (20I0). Creating workplace environments that support moral courage. The Online Journal of Issues in Nursing, 15(3). https://doi.org/ 10.3912/OJIN.Voll5No03Man04

Martin, H. (20।8, August 12). Māori and Pasifika families face discrimination, lack of support in health system - research.' Sunday Star Times.

McConnell. (2020, June 18). Black lives matter protests are about more than statues for New Zealand. New Zealand Herald.

Murray, J. S., (2010). Moral courage in healthcare: Acting ethically even in the presence of risk. The Online Journal of Issues in Nursing, 15(3). https//doi.org/I0.3912/OJIN.VolI5No03Man02

New Zealand Trade Manual. (20II, September 28). Manaakitanga: Giving New Zealand visitors an experience of true hospitality. Retrieved from https://www.newzealandtrademanual.com/manaakitanga-giving-new-zealand-visitors-an-experience-of-truehospitality

Occupational Therapy Board of New Zealand. (2015a). Competencies for registration and continuing practice. Wellington: Author. Retrieved from https://www.otboard.org.nz/wp-content/uploads/2015/04/Competencies_April20I5.pdf

Occupational Therapy Board of New Zealand. (2015b). Code of ethics for occupational therapy. Wellington: Author. Retrieved from https://www.otboard.org.nz/wp-content/uploads/2015/04/CodeofEthics_April2015-I.pdf

Parsons, R., \& Dickinson, K. (2017). Chapter 4: Ethical practice in an increasingly diverse world. In Ethical practice in the human services: From knowing to being. Thousand Oaks, CA: SAGE Publications, Inc. https://doi.org/I0.4135/978107/801147.n7

Peloquin, S. M. (2007). A reconsideration of occupational therapy's core values. The American Journal of Occupational Therapy, 6I(4), 474-478. https://doi.org//0.5014/ajot.61.4.474

Walls, J. (2020, June 15). Justice Minister Andrew Little tells Black Lives Matter movement at Parliament 'we've got to change'. New Zealand Herald. Retrieved from https://www.nzherald.co.nz/nz/news/article.cfm?c_id= I \&objectid= 12339768

Wilson, D. (2008). The significance of a culturally appropriate health service for Indigenous Māori women. Contemporary Nurse, 28(I-2), 173-188. https://doi.org/l0.5172/conu.673.28.1-2.173 